\title{
Síndrome do Ceco Móvel-Manifestações Clínicas e Avaliação Radiológica da Mobilidade do Ceco e Cólon Ascendente em Pacientes com Queixa de Constipação Crônica1
}

\author{
Mobile Cecum Syndrome - Clinical Manifestations and Radiologic \\ Avaliation of the Mobility of Cecum and Ascending Colon in Patients with \\ Chronic Constipation
}

\author{
CARLOS HENRIQUE MARQUES DOS SANTOS ${ }^{1}$, RAFAEL FONSECAMARÃO², \\ FERNANDO MÁRCIO MATOS BEZERRA ${ }^{3}$
}

${ }^{1}$ Titular da Sociedade Brasileira de Coloproctologia; ${ }^{2}$ Médico Residente em Cirurgia Geral do HRMS;
${ }^{3}$ Acadêmico do Curso de Medicina da Universidade Federal de Mato Grosso do Sul.

SANTOS CHM; MARÃO RF; BEZERA FMM. Síndrome do Ceco Móvel-Manifestações Clínicas e Avaliação Radiológica da Mobilidade do Ceco e Cólon Ascendente em Pacientes com Queixa de Constipação Crônica. Rev bras Coloproct, 2007;27(2): 174-178.

RESUMO: A síndrome do ceco móvel é uma doença causada por um mesentério relativamente alongado do ceco e segmento do cólon ascedente podendo levar a torções as quais poderiam causar micro danos vasculares impedindo a ação plena de substâncias como o peptídeo intestinal vasoativo e do óxido nítrico, fundamentais para o correto funcionamento do trato gastrointestinal. Este estudo tem como objetivo avaliar a relação entre a mobilidade do ceco e cólon ascendente (diagnosticada por exame radiológico) e a constipação crônica. Foram estudados 40 pacientes constipados, do Ambulatório de Coloproctologia do Hospital Regional de Mato Grosso do Sul (HRMS), segundo protocolo em anexo, por meio de analise radiográfica do segmento em questão. Verificouse que a maioria dos pacientes $\mathbf{( 7 2 , 5 0 \% )}$ apresentou mobilidade radiológica do ceco e cólon ascendente, e que as variáveis clínicas estudadas segundo o protocolo não são suficientes para definir esses pacientes como portadores dessa síndrome.

Descritores: constipação, dor abdominal, torção do ceco, peptídeo intestinal vasoativo, óxido nítrico.

\section{INTRODUÇÃO}

O ceco móvel é uma variação anatômica embriológica do cólon ascendente e/ou do ceco, resultante da descida incompleta desse segmento do intestino grosso e da sua não fixação no peritônio da goteira parieto-cólica direita. A falta dessa fusão permite movimentação do ceco e/ou do cólon ascendente, inclusive facilitando a torção sobre seu eixo longitudinal ou a dobra medial do ceco sobre si, ficando encostado com sua borda medial à borda medial do cólon ascendente. A anormalidade embriológica ocorre em 10 a $30 \%$ das pessoas, contudo a maior parte dos artigos médicos mencionando o problema referem quase que exclusivamente a torção completa, inadequadamente denominada de volvo do ceco-ascendente ${ }^{1}$.

O peptídeo intestinal vasoativo (VIP) regula a musculatura lisa e a secreção de água intestinal e tem importante relação com o óxido nítrico sendo que ambos têm importante efeito no trato digestivo e também nos vasos sangüíneos. A diminuição ou ausência dos mesmos pode ocasionar contrações espásticas dessas estruturas causando transtornos circulatórios do aparelho digestivo, dentre os quais a constipação ${ }^{2}$.

Sendo assim, pessoas que apresentam maior mobilidade do segmento ceco e cólon ascedente po-

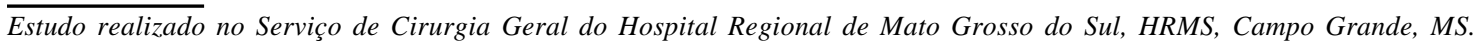

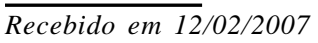

Aceito para publicação em 04/04/2007 
dem apresentar essas alterações devido a possuírem um mesocólon maior, proporcionando, em alguns casos, leves torções, que diminuem a ação do VIP e do óxido nítrico².

Essa alteração anatômica do segmento colônico em questão pode provocar uma série de sintomas que se sobrepõem, e, até mesmo, dificulta o diagnóstico de algumas doenças como por exemplo, a Síndrome do Intestino Irritável (SII) ${ }^{3}$.

Assim, diversos estudos ${ }^{1,2,4}$ têm demonstrado indícios de que a mobilidade cecal ou do segmento ceco/ascedente pode estar relacionada etiologicamente às doenças funcionais do cólon que apresentam-se com constipação como principal manifestação (constipação crônica, SII), podendo ainda causar manifestações secundárias tais como dor abdominal, distensão abdominal, flatulência, dispareunia, entre outras.

Desta forma, trabalhos clínicos que venham confirmar ou não tal relação têm, atualmente, grande importância nas áreas de coloproctologia e gastroenterologia, considerando a grande freqüência de tais queixas nos consultórios médicos.

\section{OBJETIVO}

O presente estudo tem como objetivo avaliar a relação entre a mobilidade do ceco e cólon ascendente (diagnosticada por exame radiológico), e a constipação crônica.

\section{PACIENTES E MÉTODOS}

Foram avaliados, no período de janeiro a novembro de 2006, 40 pacientes do Ambulatório de Coloproctologia do Serviço de Cirurgia Geral do Hospital Regional de Mato Grosso do Sul (HRMS) que tinham como queixa principal a constipação, segundo protocolo em anexo (Anexo1). A análise radiológica da mobilidade do ceco e cólon ascendente foi realizada pela seguinte técnica ${ }^{1}$ :

1. Os pacientes foram orientados a ingerir 150 $\mathrm{ml}$ de sulfato de bário sem preparo intestinal prévio ou alteração da alimentação habitual.

2. Foram realizadas radiografias abdominais incluindo pelve após 5 horas da ingestão da solução de bário, nas seguintes incidências:

a. Posição ortostática;

b. Decúbito dorsal; c. Decúbito lateral esquerdo com raios horizontais.

Baseado ainda no protocolo em anexo foram excluídos do estudo aqueles pacientes que apresentavam sorologia positiva para Doença de Chagas, e/ou doenças neurológicas e endócrinas que poderiam causar alteração da motilidade do trato gastrointestinal.

Considerou-se como positivo, o exame em que houve uma queda do ceco e cólon ascedente abaixo de uma linha imaginária entre as cristas ilíacas comparando a radiografia em posição ortostática com o decúbito dorsal e um desvio maior que $45^{\circ}$ do segmento analisado entre o decúbito dorsal e o lateral esquerdo com raios horizontais.

\section{RESULTADOS}

Dos pacientes estudados verificou-se que 38 eram do sexo feminino e dois do sexo masculino, com idades variando entre 20 e 78 anos (média de 41,9 anos).

Após analise radiológica do segmento ceco/ cólon ascedente dos pacientes verificou-se que 29 apresentavam alteração no exame, enquanto 11 apresentavam resultados normais (Gráfico 1).

A freqüência evacuatória dos pacientes com ceco móvel ou não encontra-se na Tabela 1.

Observou-se que 27 dos pacientes com alteração no exame radiográfico apresentavam esforço evacuatório enquanto dois não. Já entre os que apresentaram exames normais, todos referiam a queixa em questão (Tabela 2).

Vinte e cinco pacientes com alteração do exame referiram dor abdominal, sendo 19 tipo cólica e seis do tipo pontada, enquanto quatro pacientes não referiram tal queixa.

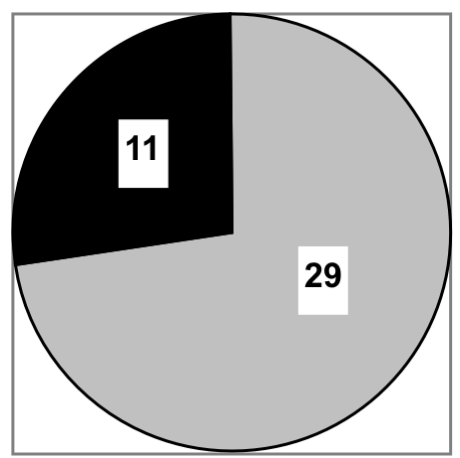

$\square$ positivo

negativo

Gráfico 1 - Distribuição dos pacientes que apresentaram ou não mobilidade do segmento ceco/cólon ascedente ao exame radiológico. 


\section{ANEXO 1}

\section{Protocolo}

1. Identificação

Data:

Nome:

Sexo:

2. Hábito Intestinal

2/2 Dias

5/5 Dias

Mais De 7 Dias

3. Esforço Evacuatório

Sim

$\square \quad$ 3/3 Dias

$\square \quad$ 4/4 Dias

$\square$ 6/6 Dias

$\square \quad 7 / 7$ Dias
Telefone: Idade:

Profissão:

4. Dor Abdominal

Sim Não

Se Sim:

$\square$ Cólica

5. Doenças Pregressas

Doença de Chagas $\square \operatorname{Sim} \quad \square \quad$ Não

$\begin{array}{lllll}\text { Cirurgia Abdominal Prévia } & \square & \text { Sim } & \square & \text { Não }\end{array}$

Doenças Endócrinas $\square$ Não

$\square$ Hipertiroidismo

$\square$ Hipotiroidismo

$\square \quad$ Diabetes Mellitus

$\square$ Feocromocitoma

Doenças Neurológicas $\quad \square$ Sim; $\quad$ Quais:

$\square \quad$ Não 
Nos pacientes com exame normal nove relataram dor, sendo oito do tipo cólica e um do tipo pontada. Apenas dois pacientes, nesse grupo, não referiram dor (Tabela 3).

Durante a análise dos pacientes a presença ou não de cirurgia abdominal prévia foi avaliada, sendo que daqueles com alteração no exame radiográfico 15 possuíam e 14 não. Dentre os que tinham exames normais, oito apresentavam procedimento cirúrgico abdominal prévio e três não (Tabela 4).

\section{DISCUSSÃO}

Alguns artigos publicados sobre a Síndrome do Ceco Móvel (SCM) referem-se ao abdome agudo como sendo causado pela torção do segmento ceco e cólon ascedente ${ }^{1,5,6}$.

Entretanto, o estudo dessa condição pode acrescentar maiores esclarecimentos a respeito de outras doenças, sendo a constipação uma de$\operatorname{las}^{1,4}$.

Tabela 1- Demonstração da freqüência de evacuação em dias entre os pacientes que apresentaram mobilidade do segmento ceco/cólon ascedente e os que não apresentaram.

\begin{tabular}{ccc}
\hline Freqüîncia de evacuações em dias & CECO MÓVEL + & CECO MÓVEL - \\
\hline $2 / 2$ dias & 4 & 2 \\
$3 / 3$ dias & 7 & 4 \\
$4 / 4$ dias & 3 & 1 \\
$5 / 5$ dias & 5 & 0 \\
$6 / 6$ dias & 3 & 0 \\
$7 / 7$ dias & 3 & 2 \\
mais de 7 dias & 4 & 2 \\
\hline
\end{tabular}

Tabela 2 - Presença ou não de esforço evacuatório nos pacientes que apresentaram ou não alteração no exame radiográfico.

\begin{tabular}{ccc}
\hline Esforço evacuatório & CECO MÓVEL + & CECO MÓVEL - \\
\hline SIM & 27 & 11 \\
N $\tilde{O} O$ & 2 & 0 \\
\hline
\end{tabular}

Tabela 3 - Queixa de dor abdominal relatada pelos pacientes com e sem alteração no exame radiográfico.

\begin{tabular}{ccc}
\hline Dor Abdominal & CECO MÓVEL + & CECO MÓVEL - \\
\hline SIM & 25 & 9 \\
N $\tilde{O}$ & 4 & 2 \\
\hline
\end{tabular}

Tabela 4 - Presença ou não de cirurgia abdominal prévia nos pacientes com e sem alteração na exame radiográfico.

\begin{tabular}{ccc}
\hline Cirurgia abdominal prévia & CECO MÓVEL + & CECO MÓVEL - \\
\hline SIM & 15 & 8 \\
NÃO & 14 & 3 \\
\hline
\end{tabular}


Pode-se observar nesse estudo que a maioria dos pacientes avaliados com constipação, segundo o protocolo em anexo, apresentaram mobilidade radiológica do ceco e segmento cólon ascedente $(72,50 \%)$ corroborando com os dados encontrados na literatu$\mathrm{ra}^{1,2,4,5,6}$.

Os pacientes estudados com essa condição, apresentaram hábitos intestinais variados assim como, os pacientes com radiografias normais. $\mathrm{O}$ esforço evacuatório foi uma queixa freqüente tanto nos pacientes com alteração no exame como naqueles que se apresentavam normais, sendo este inerente aos pacientes com queixa de constipação de uma forma geral ${ }^{4}$.

A dor abdominal foi outra queixa avaliada estando presente de forma significativa nos paciente de maneira geral, sendo caracterizada como cólica pela maioria deles, fato este observado em outros estu$\operatorname{dos}^{1,2,4}$

Observa-se desta forma que os pacientes que apresentaram alteração radiológica do ceco e segmento cólon ascedente não possuem características, segundo análise pelo protocolo em anexo, que os possam diferenciar clinicamente daqueles que possuem exames normais, fato este também observado em outros estu$\operatorname{dos}^{2,7}$

Pode ser notado ainda neste estudo que a maioria dos pacientes analisados era do sexo feminino (95\%) dado que pode ser confirmado com literatura estudada, levando ainda em consideração a associação entre a SCM e a SII ${ }^{1,3}$

A distensão assimétrica do abdome também pode ser observada em pacientes com queixa de constipação crônica, fato que pode ser aliviado com uso de laxantes ${ }^{4}$. Esse dado não foi observado no estudo em questão.

Pode ser concluído que os pacientes portadores de constipação intestinal crônica apresentam, em sua maioria, alteração radiológica da posição do ceco e cólon ascedente, e que as variáveis clínicas dos mesmos não são suficientes para estabelecer se há ou não relação entre a mobilidade do segmento estudado e as manifestações clínicas.

ABSTRACT: Mobile cecum syndrome is a disease caused by the failure of the right colon fusion with the lateral peritoneum. It might lead to volvulus which could cause micro vascular damages preventing the full action of substances such as the intestinal vasoactive peptide and nitric oxide. These substances are necessary to the correct gastrointestinal function. The objective of this study is to evaluate the relationship between the mobility of cecum and the right colon (diagnosed by radiological examination) and the chronic constipation. Forty constipated patients, from the Clinic of Coloproctologia of the Hospital Regional de Mato Grosso do Sul (HRMS), in accordance with the attached protocol were studied through radiological analysis. It was observed that the majority of the patients $(\mathbf{7 2 , 5 0 \%})$ presented radiological mobility of the cecum and right colon and that the clinical variable studied according to the protocol are not enough to define these patients as mobile cecum syndrome patients.

Key words: constipation, abdominal pain, cecum volvulus, vasoactive intestinal peptide, nitric oxide.

\section{REFERÊNCIAS}

1. Santos Júnior JCM, Cavalca AN, Caso CEQ Síndrome do ceco móvel - Mito ou Realidade. Rev bras Coloproct 2004;24(2):153-158.

2. Gusmán AB, Suárez B, Martinez L, Sitchao N, Ruiz J, Martinez NA, Carrazana LA, Fundora E, Méndez F, Martinez E. El Ciego Móvil, puede dar origen a Megarecto y Megacolon adquirido com alteraciones morfológicas neuronales y de la pared intestinal. Coloproctologia Atual- J.A. Reis Neto. http:/ /www.proctosite.com/library/books/livro_reis_novo/ index_coloproc_atual.htm

3. Santos Júnior JCM. Alteração Congênita de Fixação do Segmento Ceco Ascendente dá Sintomas Iguais ao da Síndrome do Cólon Irritável. Rev bras Coloproct 2005;25(0)361-369.
4. Santos Júnior JCM. Constipação Intestinal. Rev bras Coloproct 2005;25(1):79-93.

5. Merlo CV, Covatti EL, Zanin RL, Madalosso CA. Volvo de ceco / Volvulum of cecum Rev. med. Hosp. Säo Vicente de Paulo 1994; 6:52-4.

6. Ismail A. Recurrent colonic volvulus in children. J Pediatr Surg 1997;32:1739-42.

7. Rogers RL, Harford FJ. Mobile cecum syndrome. Dis Colon Rectum. 1984 Jun;27(6):399-402.

Endereço para correspondência:

CARLOS HENRIQUE MARQUES DOS SANTOS

Rua Aluízio de Azevedo, 606 - São Bento

79004050 - Campo Grande - MS

Fax: 33259528

E-mail: chmarques@terra.com.br 